\title{
Transcription factor recruitment by parallel G-quadruplexes to promote transcription: the case of herpes simplex virus-1 ICP4
}

\author{
Ilaria Frasson, Paola Soldà, Matteo Nadai, Sara Lago, Sara N. Richter*
}

Correspondence: sara.richter@unipd.it, SaraNRichter_

Department of Molecular Medicine, University of Padua, via A. Gabelli 63, 35121 Padua, Italy

\section{SUMMARY}

G-quadruplexes (G4s), four-stranded nucleic acid structures that adopt several distinctive conformations, are abundant at gene promoters and have been proposed as transcription regulatory elements. G4s form in the herpes simplex virus-1 (HSV-1) genome during its viral cycle. Here by cross-linking/pull-down assay we identified ICP4 as the protein that most interacts with viral G4s during infection. In vitro and in infected cells, ICP4 specifically and directly bound and unfolded parallel G4s, including those present in HSV-1 immediate early gene promoters, and consequently induced transcription. This mechanism was also exploited by ICP4 to promote its own transcription. By proximity ligation assay we visualized ICP4 interaction at the single G4 in cells. G4 ligands inhibited ICP4 binding to G4s. Our results indicate the existence of a well-defined G4viral protein network that regulates the productive HSV-1 cycle. They also point to G4s as elements that recruit transcription factors to activate transcription in cells.

\section{KEYWORDS}

Parallel G-quadruplexes, Herpes simplex virus-1 HSV-1, ICP4, transcription factor, transcription regulation, unfolding, cross-linking pull-down, proximity ligation assay, BG4 antibody, G-quadruplex ligand

\section{INTRODUCTION}

DNA can adopt a variety of non-canonical structures that play important functional roles (Tateishi-Karimata and Sugimoto, 2020). G-quadruplexes (G4s), secondary structures that form in guanine-rich regions, are among the most stable non-canonical structures (Spiegel et al., 2020). G-quartets, the building blocks of $\mathrm{G} 4 \mathrm{~s}$, are formed by an extensive hydrogen-bonding network that links four guanine bases around a cationic core. G4 structures comprise G-quartets stacked upon each other, stabilized by base stacking between the layers. G4s are highly polymorphic and can adopt different topologies (i.e. parallel, antiparallel or hybrid topology), based on strand stoichiometry and polarity, the nature and length of the loops and their location in the sequence (Hänsel-Hertsch et al., 2017). At the cellular level, the parallel G4 conformation is the most widespread since it is adopted by RNA G4s (Collie et al., 2010) and by many DNA G4s in physiological conditions (Agrawal et al., 2014; De Nicola et al., 2016; Mathad et al., 2011; Monsen et al., 2020). In addition, it is functionally recognized by G4 interacting antibodies and proteins (Carle et al., 2016; Liu et al., 2016; Roach et al., 2020; Schierer and Henderson, 1994). 
Intense effort has been directed towards predicting and identifying DNA G4 structures in the genome of humans and of the most important human pathogens (Bedrat et al., 2016; Lavezzo et al., 2018; Sahakyan et al., 2017). G4 folded/unfolded state modulates numerous processes, including replication, transcription, translation and can trigger genomic instability (Gray et al., 2014; Hänsel-Hertsch et al., 2017; Prorok et al., 2019; Wang et al., 2019). G4-forming sequences are highly represented in the genomes of all living beings (Bartas et al., 2019)(Hänsel-Hertsch et al., 2017; Marsico et al., 2019), indicating that these structures are likely exploited as regulatory elements, while their negative effects can be mostly avoided (Spiegel et al., 2020). Characterization of the G4-protein interactome in some cases allowed the deep understanding of the G4-mediated biology (Haeusler et al., 2014).

G4-ligands are molecules that selectivity target G4s by differentiating them from the double-stranded DNA; in principle they can also selectively target the specific G4, based on its structural uniqueness, and indeed some degree of selectivity has been reported by different strategies (Asamitsu et al., 2019; Jin et al., 2014; Nadai et al., 2018; Perrone et al., 2015; Tassinari et al., 2020; Voter et al., 2018).

The human herpesviruses constitute a large family of dsDNA viruses, which are the causative agents of a wide range of diseases, spanning from oral/genital blisters to cancer. In particular, herpes simplex virus 1 (HSV-1) infects $\sim 70 \%$ of the adult population, establishing a latent neuronal infection which, upon stressful conditions, may be reactivated to a lytic symptomatic state. HSV-1 is the major cause of blindness and viral encephalitis worldwide (Koujah et al., 2019). HSV-1 life cycle is characterized by a coordinated and sequential cascade of expression of three temporal classes of viral genes: the viral tegument protein VP16 prompts transcription of the immediate early (IE) viral genes, the products of which in turn activate transcription of the early $(E)$ and late $(L)$ viral genes; transcription of the late viral genes is also coupled to viral DNA replication (Dembowski and DeLuca, 2018). We have previously demonstrated that biologically significant and highly conserved G4s are present in crucial elements of the HSV-1 genome, in particular, within repeated regions and in immediate early gene promoters, which control the viral life cycle (Artusi et al., 2015; Frasson et al., 2019). Viral G4s are observable in infected cells with peak signals during HSV-1 DNA replication (Artusi et al., 2016).

Here we show that the viral transcription factor ICP4, which is expressed soon after infection and sustains the HSV-1 viral cycle, displays significant binding preference for parallel G4s. This essential viral protein unfolds G4s in viral promoters and thereby regulates HSV-1 viral gene expression. We show that the physical interaction between ICP4 and the viral G4s is detectable in infected cells and that ICP4 modulates its own promoter via G4-mediated interaction. Our results indicate the existence of a well-defined G4-viral protein network and of previously unexplored viral strategies that regulate the productive HSV-1 cycle.

\section{Results}

\section{HSV-1 transcription factor ICP4 binds to G4-folded nucleic acids}

We have recently demonstrated that the HSV-1 genome is significantly enriched in conserved G4 patterns and that the amount of G4s that form in HSV-1-infected cells depends on the viral step, being the highest during viral DNA replication (Artusi et al., 2015, 2016). To gain further insights into the G4-dependent virus biology, we set out to identify viral/cellular proteins that could specifically interact with biotinylated G4forming HSV-1 sequences. We employed two sequences that have been previously reported to fold into G4s and be highly repeated within the HSV-1 genome: the 58 nt-long un2L2 and 66 nt-long gp054dL3 G4-folding 
oligonucleotides (Table S1), which are highly conserved and repeated within the terminal and internal repeat short regions (TRS and IRS, RS2) and the UL36 coding sequence (CDS, UL RS1), respectively (Artusi et al., 2015; Callegaro et al., 2017). Un2L2 is composed of 9 G-tracts, ranging from three to nine $G$ bases each, gp054dL3 of ten G-tracts of 4-8 Gs each. Two additional G4-forming sequences were used: the $28 \mathrm{nt}$-long LTR-III from the HIV-1 LTR promoter (6 G-tracts of 2-3 Gs) (Butovskaya et al., 2018; Perrone et al., 2013), and the 26 nt-long myc G4-forming region from the myc oncogene promoter (6 G-tracts of 2-4 Gs) (Calabrese et al., 2018; Yang and Hurley, 2006) (Table S1). These two sequences were used as positive controls, representing well characterized viral and cellular G4s, respectively. Circular dichroism (CD) spectra were acquired to characterize the G4 conformation of the test sequences, since CD peaks represent signatures of the parallel (positive and negative peaks at 260 and $240 \mathrm{~nm}$, respectively), antiparallel (positive and negative peaks at 290 and $260 \mathrm{~nm}$, respectively) and hybrid or mixed topology (positive peaks at 290 and $260 \mathrm{~nm}$ ) (del Villar-Guerra et al., 2018). Biotinylated un2L2 and myc form parallel G4s, characterized by a main peak at $260 \mathrm{~nm}$ and no peak at $290 \mathrm{~nm}$ (signal ratio at 260/290 nm of 13.7 and 10.9, respectively) (Figure S1); in contrast, biotinylated LTR-III and gp054dL3 display a hybrid/mixed conformation, characterized by CD peaks at both 260 and $290 \mathrm{~nm}$ (signal ratio $260 / 290 \mathrm{~nm}$ of 3.1 and 0.8 , respectively). A G-rich sequence, unable to fold into G4, was used as control (Table S1 and Figure S1). These oligonucleotides were next incubated with nuclear extracts from U-2 OS human osteosarcoma cells infected with HSV-1 strain F (Multiplicity of Infection, MOI of 2). U-2 OS cells are susceptible and permissive to HSV1 (Suk and Knipe, 2015). Nuclear extracts were collected at 8 hours post infection (hpi); the HSV-1-derived oligonucleotide un2L2 was additionally analysed at $16 \mathrm{hpi}$. These two time points were chosen to analyse proteins present during viral DNA replication (8 hpi), i.e. proteins involved in transcription, DNA replication, chromatin remodelling and RNA processing, and at the final step of virion maturation (16 hpi), i.e. proteins involved in post-transcriptional RNA processing and viral structural proteins (Dembowski and DeLuca, 2015, 2018). The proteins bound to the un2L2 bait were subjected to SDS PAGE/mass spectrometry (MS): data were analyzed by Mascot software (Domon and Aebersold, 2006), which assigns a score based on the number of fragments that match the recognized protein and the probability that the observed match is not a random event. Results are summarized in Table S2: only proteins with score $>30$ in duplicate experiments and displaying selectivity towards the G4 structure, (i.e. score on the G4 at least 100 times higher than the score on the G-rich sequence unable to form G4) were retained. At 8 hpi, five viral (UL42, ICP4, DUT, UL23) and two cellular (HNRNPA1L2 and NCL) proteins, all involved in transcription regulation and replication, were retrieved. At $16 \mathrm{hpi}$, three additional viral proteins were recovered: UL18, UL19 and UL38, all of which are part of the viral encapsidation machinery (Heming et al., 2017). At this time post-infection, despite the relative increase in structural proteins including tegument proteins, UL42 and ICP4, two proteins recovered at $8 \mathrm{hpi}$ and belonging to the replication and transcription machinery, retained the most efficient G4 binding. No additional proteins were recovered with the other G4 baits: ICP4, UL42, UI19 with gp054dL3; ICP4 with LTR-III; UL23, ICP4, UL42 and UL19 with myc (Table S2). ICP4 was the only protein that interacted with the four G4 baits and, interestingly, its Mascott score was proportional to the G4 bait 260/290 nm ratio, i.e. with the degree of G4 parallel conformation. 
We thus selected ICP4 for further investigation. To assess if ICP4 directly interacted with the tested G4s, we set up a cross-linking-pull-down assay coupled to western blot (WB) to detect only proteins directly interacting with the test oligonucleotides (Hoffman et al., 2015). ICP4 binding was assessed against several G4s: un2L2 and its shorter sequence un2 from the HSV-1 genome (Artusi et al., 2015); LTR-III and its longer sequence LTR-II+III+IV from the HIV-1 genome (Perrone et al., 2013); myc from the human genome (Yang and Hurley, 2006). The chosen sequences differed in length (from 26 to $58 \mathrm{nt}$ ) and topology (parallel or hybrid, identified by $260 / 290 \mathrm{~nm}$ ratio in the range of $0.8-14.0$, Figure $1 \mathrm{~A}$ and Table S1). The cross-linkingpull-down assay confirmed that ICP4 directly binds to the G4s (Figure 1B), with clear preference for G4s with high 260/290 nm ratio, thus those with a parallel topology, such as un2L2, un2 and myc. In contrast, oligonucleotide length was not a determinant of recognition, as we observed negligible difference between un2 and un2L2 (29 vs 58 nts, respectively), and LTR-III and LTR-II+III+IV (28 vs 45 nts, respectively) sequences (Figure 1B).
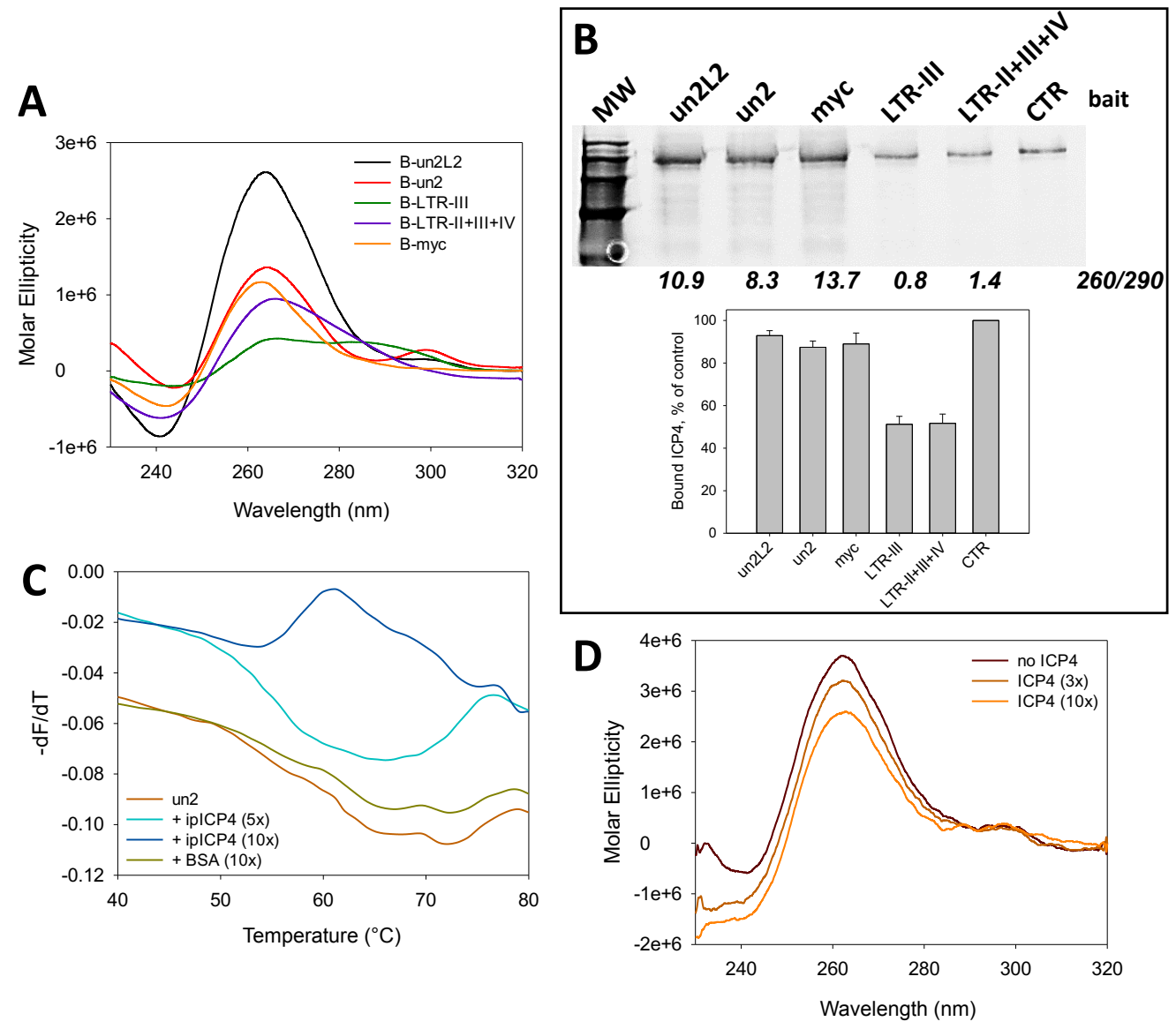

Figure 1. ICP4 binding and unfolding of G4-folded oligonucleotides. (A) CD spectra of the biotinylated oligonucleotides used in the cross-linking-pull-down assay, folded in potassium phosphate buffer $(20 \mathrm{mM}$ $\mathrm{PB}, 80 \mathrm{mM} \mathrm{KCl}$ ). (B) Western Blot analysis of ICP4 binding to the indicated G4s (viral: un2L2, un2, LTR-III, LTR-II+III+IV; cellular: myc). Infected cell nuclear extracts $(5 \mu \mathrm{g})$ were incubated with formaldehyde-activated G4-folded oligonucleotides; proteins bound to the G4s were eluted after high stringency washes. ICP4 was detected by the anti-ICP4 antibody and CTR is a control lane loaded with infected cell nuclear extracts (3.5 $\mu \mathrm{g})$ not subjected to the pull-down procedure. MW: molecular weight (Marker VI, Applichem). Below the gel image, the 260/290 ratio for each biotinylated oligonucleotide is displayed. Quantification of ICP4 bound to the G4s is indicated in the bar chart (average of two independent experiments, SD is displayed). Band quantification was normalized for the protein amount loaded per well and to the CTR sample (5 $\mu \mathrm{g}$ in G4 
lanes, $3.5 \mu \mathrm{g}$ in CTR). (C) First derivative FRET-melting curves (-d $F_{525} / \mathrm{dT}$ vs T) of F-un2-T G4 oligonucleotide treated with ICP4 or BSA at the indicated protein/DNA ratios, in $20 \mathrm{mM} \mathrm{PB} \mathrm{pH} \mathrm{7.4,} 2 \mathrm{mM}$ $\mathrm{KCl}$. (D) CD spectra showing the unfolding (molar ellipticity reduction) of un2L2 G4 in the presence of increasing ufICP4 concentrations. The protein spectrum was subtracted from DNA-protein complex spectra.

To assess the activity of ICP4 on G4s, we purified ICP4 from infected cells via immunoprecipitation (ipICP4) using a monoclonal anti-ICP4 antibody (Ab) or via ultrafiltration (ufICP4) (Imbalzano et al., 1990). In the first case we obtained low amounts of very pure protein, in the second larger amounts with acceptable purity. The purity and identity of the protein were confirmed by WB and mass spectrometry (MS) analysis (Figure S2). Both ipICP4 and ufICP4 were used to assess their activity on fluorescence labeled G4 oligonucleotides by fluorescence resonance energy transfer (FRET) analysis. As the main determinant of the FRET signal is the distance between the donor (FAM) and acceptor (TAMRA) fluorophores, when these are linked to the 5' and 3'-end of a G4-forming oligonucleotide, the intensity of the FRET signal is directly proportional to G4 folding. We first ascertain that the presence of the FAM and TAMRA fluorophores at the 5'- and 3'-end, respectively, of the test G4s, i.e. two viral (un2 and LTR-III) and two cellular (myc and hTel) G4s, induced only minor modifications on their overall $\mathrm{G} 4$ topology and melting temperature, as proven by $\mathrm{CD}$ analysis (Figure S3A and Table S1): un2 and myc maintained their parallel (260/290 value of 25.0 and 52.2, respectively), and LTR-III and hTel their hybrid G4 conformation (260/290 value of 1.2 and 0.3 , respectively). The fluorescence signal and its variation upon incubation with ICP4 allowed to calculate the energy transfer $(E)$ and end-to-end distance $(R)$ between the two fluorophores, and therefore the degree of $G 4$ folding. In the case of un2 and myc, addition of ipICP4 induced unfolding, the degree of which largely or mildly increased when the G4 complementary strand was added before or concurrently to ipICP4, respectively (Table S3 and Figure 1C). Addition of the complementary strand alone induced only minor unfolding, while the control BSA protein did not show any effects. Unfolding was more pronounced on myc than un2 likely because of the lower initial stability of myc that forms a three-tetrad G4, vs un2, which is a four tetrad G4 (Scalabrin et al., 2017a) (Table S3 and Figure S3B-E). Similar unfolding with increased efficiency was obtained when ufICP4 was used. The improved activity was likely due to the milder purification conditions of ufICP4 vs ipICP4. When BRACO-19 (B19), a documented stabilizing G4 ligand (Burger et al., 2005), was added, we observed stabilization of un2. When ufICP4 was added concurrently to B19, the unfolding degree was much lower than that induced by ufICP4 alone, indicating that B19 was able to partly inhibit ICP4 unfolding activity (Table S3). In contrast, negligible ICP4-mediated unfolding was observed on the hybrid G4s, i.e. LTR-III and hTel.

CD was next employed to further investigate ICP4 unfolding activity. UfICP4 was used because CD requires much higher protein amounts than FRET. First, we measured CD spectra of the unlabeled oligonucleotides (Figure S4): we noticed that the unlabelled un2 folded into antiparallel G4, in line with previously reported evidence that end modifications may modify the overall G4 topology (Parkinson et al., 2002; Vorlíčková et al., 2012); in contrast, its longer sequence, un2L2, maintained the parallel G4 conformation. The unlabelled myc and LTR-III/hTel also maintained the parallel and mixed conformation, respectively, observed with the labelled oligonucleotides. ICP4 decreased the CD signal, i.e. unfolded, of the parallel un2L2 and myc G4s, while had no effect on the antiparallel un2 (Figure 1D and S4), data that clearly confirm the G4 topologyrather than G4 sequence-dependence of ICP4 activity. In addition, the CD signal of LTR-III, reported to fold into a 3+1 hybrid G4 (Butovskaya et al., 2018), was decreased to a negligible extent, while only the signal corresponding to the parallel topology was affected in hTel, which adopts several different conformations in 
solutions (Heddi and Phan, 2011) (Figure S4). The decrease in molar ellipticity was proportional to the 260/290 value: higher with 260/290 value > 10 (parallel G4s); lower with 260/290 value $>0$ and < 1 (hybrid G4s); null for 260/290 value < 0 (antiparallel G4s). These in vitro data indicate that ICP4 specifically binds and unfolds parallel G4s, favouring duplex formation.

\section{ICP4-G4 interaction takes place in the nucleus of infected cells during HSV-1 infection}

To verify ICP4 interaction with HSV-1 G4s in the infected cells, we first investigated the actual G4 folding of the un2 sequence in HSV-1 infected U2-OS cells by FISH analysis with a biotinylated DNA probe that does not fold into $G 4$ and partially overlaps with the un2 sequence without hindering its $G 4$ folding; we visualized G4s with an anti-G4 Ab (Biffi et al., 2013) (Table S1). The majority of the un2 signal co-localized with the G4 $\mathrm{Ab}$ (Figure 2A and S5), indicating that un2 is indeed folded into $\mathrm{G} 4$ in cells in these conditions. The proximity ligation assay (PLA) (Fredriksson et al., 2002) was next employed to prove ICP4 direct binding to the viral folded G4s in cells, as the PLA signal is detectable only when two macromolecules of interest are in close proximity $(<40 \mathrm{~nm})$, thus directly interacting. We used the biotinylated DNA probe partially overlapping with un2 (Figure S6A) and an anti-ICP4 monoclonal antibody. We infected cells with HSV-1 at MOI 3, that, according to the Poisson's distribution, allows infection of up to 95\% cells, and we looked for PLA at 8 hpi. PLA dots were visible in the nucleus of infected cells (Figure 2B and S6B). We recorded one spot per nucleus in independent experiments in the majority of PLA positive cells (75\%), whereas the remaining $(25 \%)$ were characterized by two dots per nucleus. This observation perfectly fits with the evidence that just the single parental genome is transcribed in each cell where ICP4 acts as transcription factor (Everett and Murray, 2005; Everett et al., 2003) and that, despite the high MOI used, only a small portion of cells is infected by multiple parental viral genomes (Cohen and Kobiler, 2016). These data indicate that the essential HSV-1 transcription factor ICP4 directly binds to viral folded G4s in cells during HSV-1 infection.

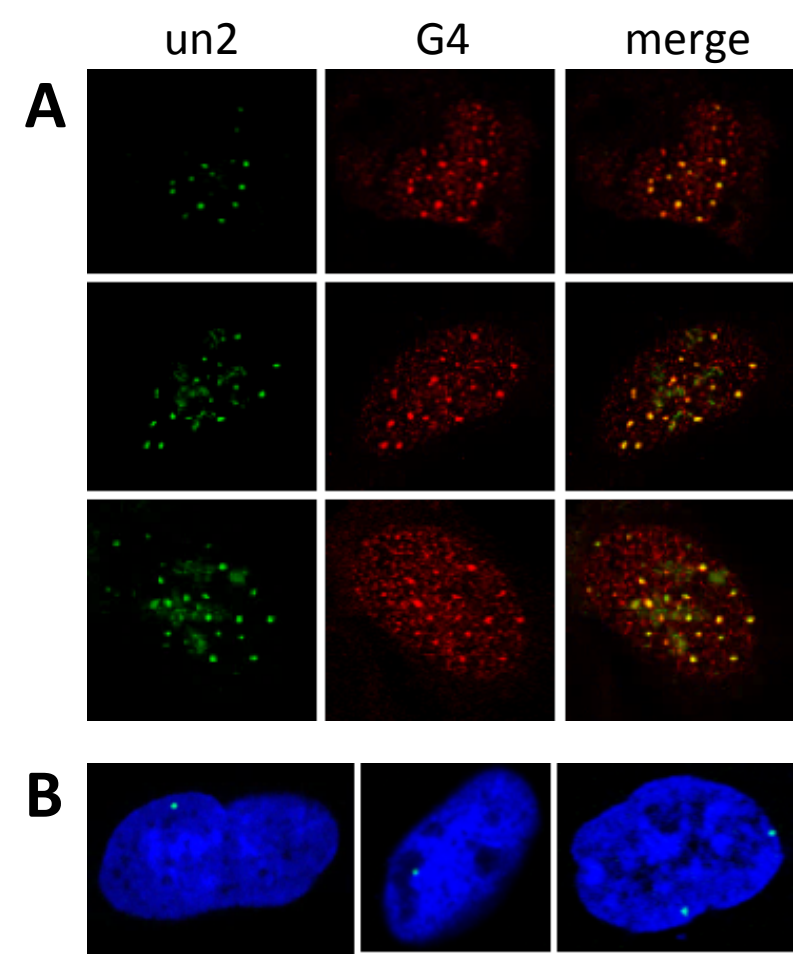


Figure 2. ICP4 and un2 G4 colocalization in the nucleus of HSV-1 infected cells. (A) Representative images of immuno-DNA-FISH in U-2 OS cells infected with HSV-1, strain F, MOI of 3, fixed at 8 hpi. The green and red signals correspond to un2 $\mathrm{G} 4$ and anti-G4 Ab signals, respectively; the merged signals are in yellow. Controls are shown in Fig. S5; (B) Representative images of proximity ligation assay (PLA) in U-2 OS cells infected with HSV-1, strain F, MOI of 3, fixed at 8 hpi. The green dots (PLA signal) correspond to G4ICP4 interaction (one or two dots per nucleus). The blue signal corresponds to TOTO3 nuclear staining. Controls are shown in Fig. S6.

Biological role of ICP4-G4 interaction: ICP4 positively regulates its own promoter via G4 interaction ICP4 has been reported to function as regulator of HSV-1 gene promoters, including its own (Didonato and Muller, 1989; Gu et al., 1995; Kuddus et al., 1995; Tedder et al., 1989). When the promoter regions in between the TATA-box and TSS were analysed, ICP4 was reported to recognize a rather degenerated consensus sequence (i.e. RTCGTCNNYNYSG, where $R$ is purine, $Y$ is pyrimidine, $S$ is $C$ or $G$, and $N$ is any base) (DiDonato et al., 1991; Kuddus et al., 1995; Tunnicliffe et al., 2017), while analysis of the full-length promoter regions highlighted several $G$ residues as key elements in ICP4 recruitment and transcription regulation (Didonato and Muller, 1989; Tedder et al., 1989). We have recently proved that HSV-1 IE promoters, including that of ICP4, are characterized by the presence of multiple and conserved G4s (Frasson et al., 2019). In particular, from the TATGARAT signal to the ATG start codon, the ICP4 promoter displays three G4s on the leading strand and one on the lagging strand. All sequences form parallel-like G4s and display high stability (Table S1 and Figure S7). Given these observations and since our above data indicate a clear ICP4 preference for binding and unfolding parallel G4s, we investigated whether ICP4 recognizes its own promoter at the G4 level. We set up a pull-down assay to estimate ICP4 binding towards the G4 sequences embedded in its promoter. The reported ICP4 consensus sequence (DiDonato et al., 1991; Kuddus et al., 1995; Tunnicliffe et al., 2017) was used as positive control; a G-rich non-folding sequence (scrambled, S) was used as negative control (Table S1). ICP4 bound all ICP4-promoter G4s, as well as the reported consensus sequence (Figure 3A): the two best bound sequences were ICP4-146532 and ICP4-146666, both of which display high 260/290 values (> 50); the other two sequences were also efficiently recognized (low ICP4 signal in the unbound fraction, Figure $3 \mathrm{~A}$ ) but the quicker dissociation rates, proved by ICP4 signal in the fractions treated with a low stringency buffer (ICP4 signal in the wash fraction, Figure 3A), indicated lower affinity. These two latter G4s have lower 260/290 values ( 10). CD analysis confirmed the unfolding activity of ICP4 on its own promoter region: ICP4 reduced molar ellipticity of all the four ICP4 G4 sequences, especially in the region that corresponds to the signal of the parallel G4 topology (i.e. wavelength $<270 \mathrm{~nm}$ ) (Figure $3 \mathrm{~B}$ ). 

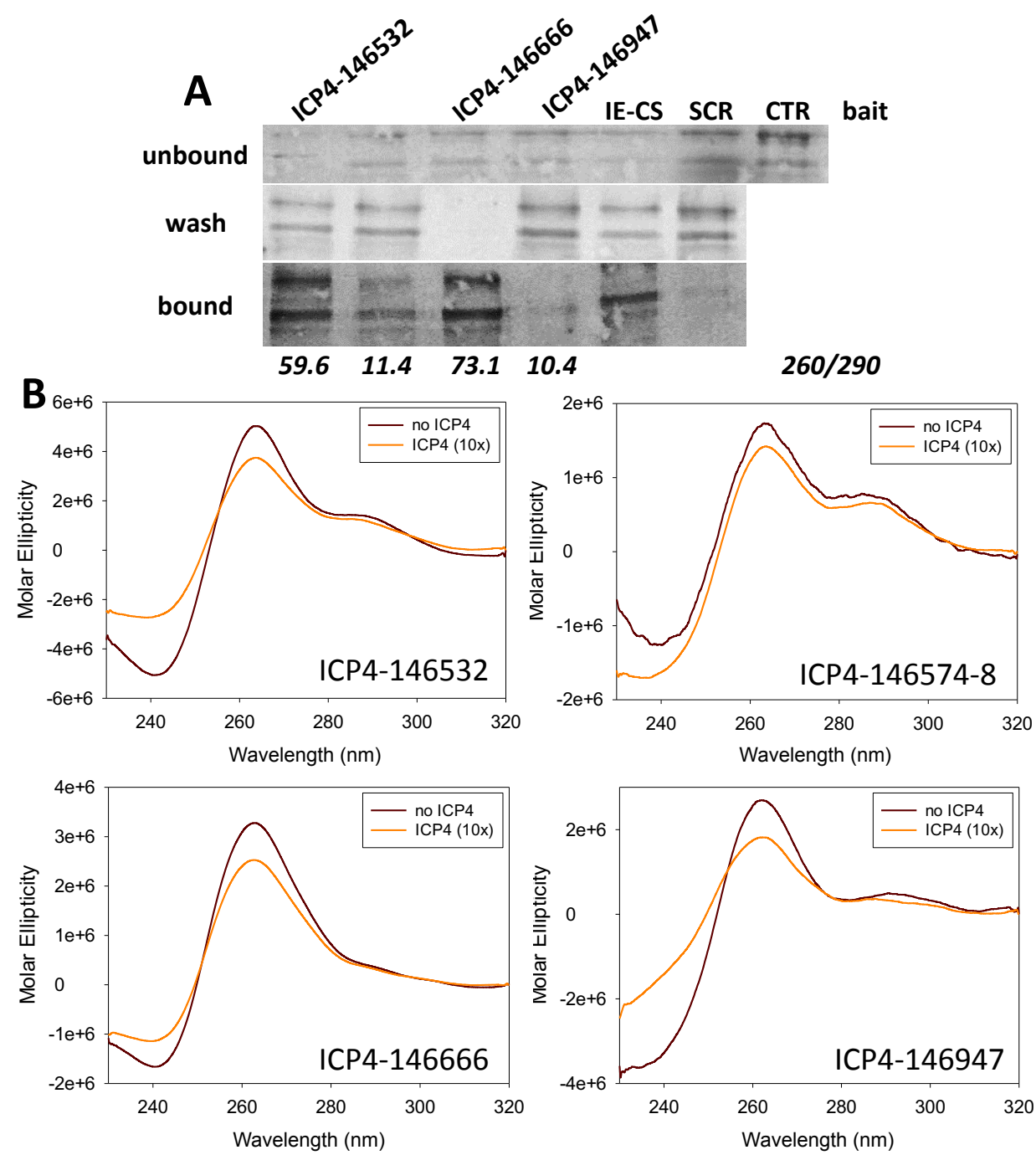

Figure 3. ICP4 binding and unfolding of G4 sequences embedded in the ICP4 promoter. (A) Western blot analysis of ICP4 cross-linking pull-down towards the indicated four G4s embedded in the ICP4 promoter. IE-CS is the reported ICP4 consensus sequence (DiDonato et al., 1991; Kuddus et al., 1995; Tunnicliffe et al., 2017); SCR is a G-rich unfolded oligo; CTR is a control lane loaded with infected cell nuclear extracts not subjected to the pull-down procedure. The upper panel shows the unbound ICP4 fraction, the middle panel the washed out ICP4 fraction, the lower panel the ICP4 fraction bound to each oligo. The multiband appearance of ICP4 from HSV-1 infected cells in WB has been reported (Wagner and DeLuca, 2013) and reflects the presence of differently post-transcriptionally processed isoforms. (B) CD spectra of the indicated G4 sequences embedded in the ICP4 promoter folded in potassium phosphate buffer $(20 \mathrm{mM} P B, 2 \mathrm{mM}$ $\mathrm{KCl}$ ) and incubated in the absence/presence of uflICP4 (10x). ICP4 spectrum was subtracted from G4-ICP4 complex spectra.

We next proceeded to assess G4-mediated ICP4 activity on its own expression in cells. To this purpose we cloned the ICP4 promoter complete sequence (nts 146488-147065 NCBI Reference Sequence: NC_001806.2) upstream of the firefly luciferase gene in a promoterless plasmid. To evaluated ICP4 activity on its own promoter, we transfected increasing amounts of a mammalian ICP4 expression vector (Everett et al., 2003) (Figure 4A) $24 \mathrm{~h}$ prior to the ICP4 luciferase reporter vector to allow ICP4 to be expressed. ICP4 promoter activity was remarkably upregulated $(2000 \%$ at the highest ICP4 concentration) by ICP4 expression, while the TK promoter was only marginally affected, as previously reported (Xiao et al., 1997) 
(Figure 4B). The augmented ICP4 promoter activity in the presence of ICP4 is in line with the observed ability of ICP4 to unfold G4s.

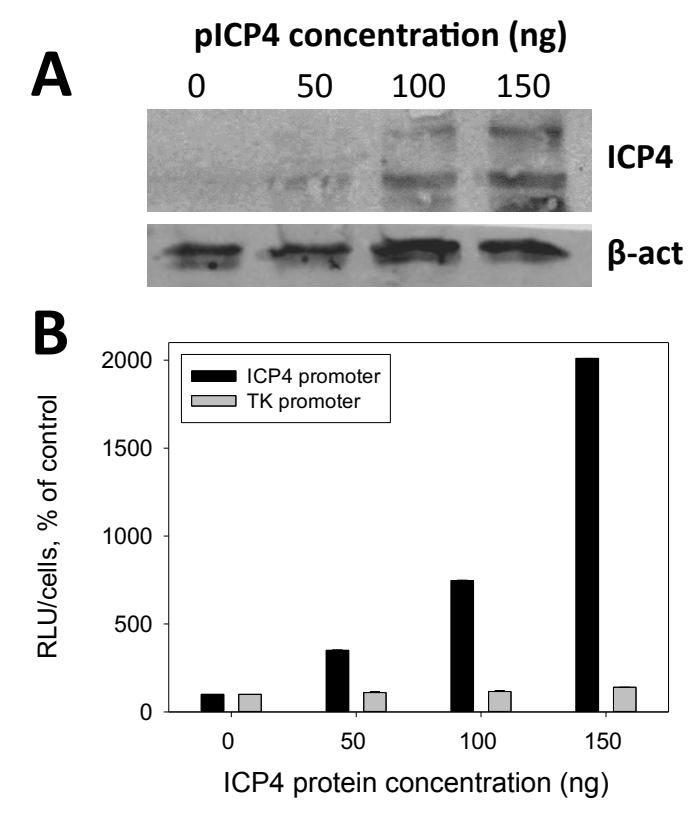

Figure 4. G4-mediated ICP4 promoter regulation by ICP4 in cells. (A) Western blot analysis of ICP4 expression in the presence of increasing amounts of ICP4 expression plasmid in transfected U-2 OS cells. ICP4 and TK promoters were cloned in the promoterless pGL-4.10 plasmid upstream of the luciferase gene and transfected into U-2 OS cells. $\beta$-actin was used as housekeeping control for cell amount (B) Luciferase reporter assay of ICP4 and TK promoter activity in the presence of increasing amounts of ICP4 protein from ICP4 expression plasmid.

To prove the G4-dependence of the ICP4 promoter we analysed its activity in U-2 OS cells in the presence of the G4 ligand B19. A control vector with Renilla luciferase under the HSV-1 TK promoter was used as negative control, as the TK promoter does not contain significant putative folding sequences (Biswas et al., 2016). We observed B19 concentration-dependent inhibition of ICP4 promoter activity, while both TK promoter activity and cell viability were not affected by B19 (Figure 5A). B19 was able to inhibit ICP4mediated increased promoter activity by 10 folds when administered after transfection of the ICP4 promoter plasmid. This inhibitory activity improved up to 65 folds when B19 was administered before transfection of the ICP4 promoter plasmid (Figure 5B), indicating that B19 effectively competes with ICP4 for the binding to the G4s in the ICP4 promoter. The TK promoter, used as negative control, showed no response to both ICP4 and B19 at both times (Figure 5B) also in this case. Similar reduction levels were obtained upon treatment with B19 of a plasmid expressing ICP4-YFP (Yellow Fluorescence Protein) under the ICP4 promoter (Figure 5C). In addition, treatment of HSV-1 infected U-2 OS cells with B19 reduced ICP4 expression at 24 hpi up to $88 \%$ of the untreated control (Figure 5D). The similar inhibition rates obtained in virus- and plasmid-triggered protein expression under the same ICP4 promoter and, presenting different expressed proteins (i.e. native ICP, ICP4-YFP and luciferase), strongly suggest that the G4-ligand B19 inhibits transcription in infected cells acting at the G4s embedded in the ICP4 promoter and point to the presence and functional relevance of G4s in ICP4 promoter in cells. 

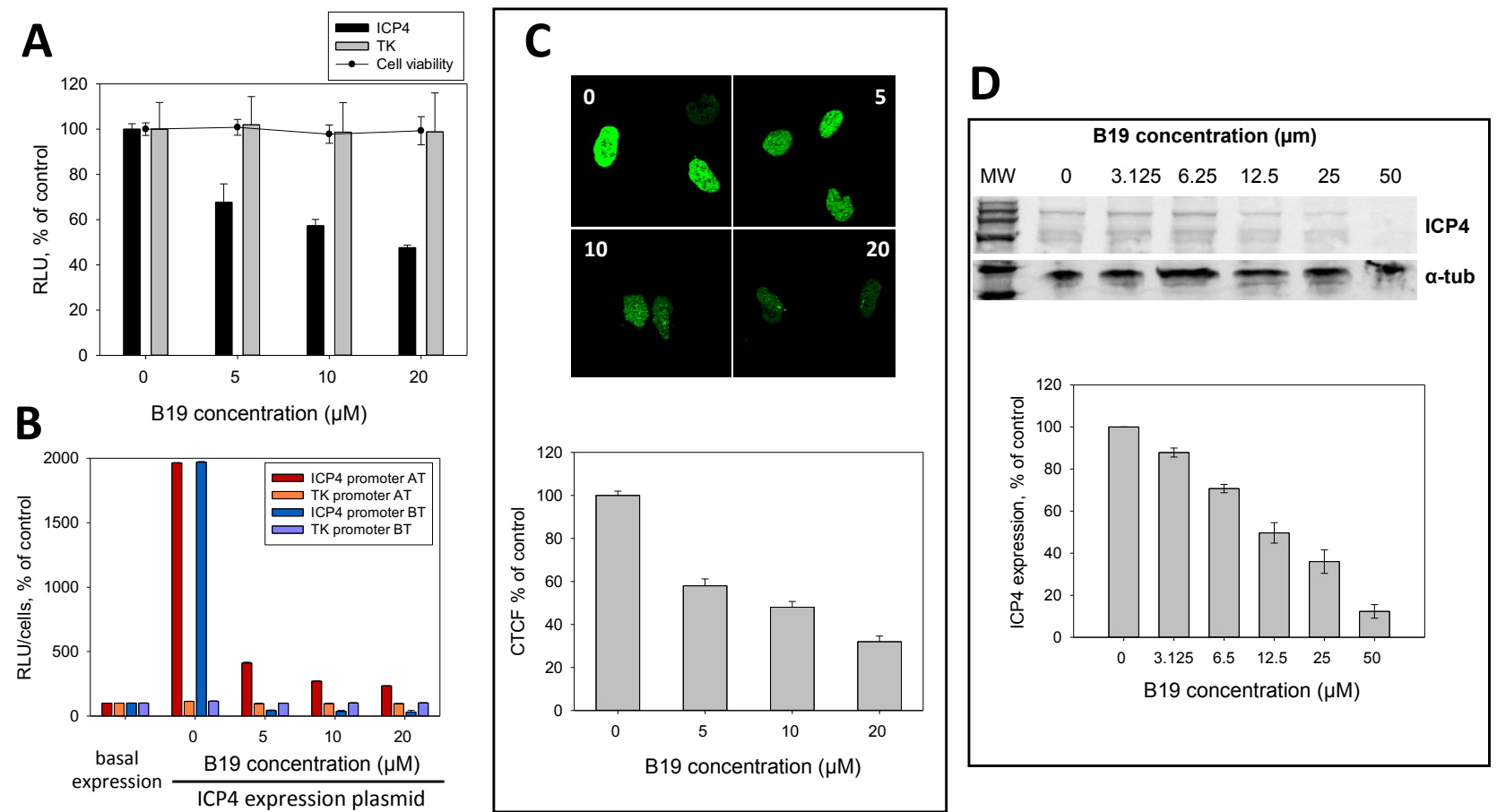

Figure 4. ICP4 expression in the presence of the G4-ligand B19. (A) Luciferase reporter assay of ICP4 promoter and control TK promoter activity in the presence of increasing B19 concentrations. ICP4 and TK promoters were cloned in the promoterless pGL-4.10 plasmid upstream of the luciferase gene and transfected into U-2 OS cells. U-2 OS cell viability in the presence of increasing concentrations of B19 was also evaluated. (B) Luciferase reporter assay of ICP4 and TK promoter activity in the presence of ICP4 expression plasmid and in the presence/absence of B19 added $2 \mathrm{~h}$ after (AT) or before (BT) transfection of reporter plasmid. (C) Upper panel: representative confocal microscopy images of U-2 OS cells transfected with ICP4-EYFP plasmid that express EYFP under the ICP4 promoter, in the presence of increasing concentrations of $\mathrm{B} 19(0,5,10,20 \mu \mathrm{M}$, as indicated). Lower panel: quantification expressed as corrected total cell fluorescence (CTCF) of cell images, calculated on 6-8 slides (50-100 nuclei), mean average levels from two independent experiments. (D) Western blot analysis (left) and quantification (right) of the viral ICP4 protein in the presence of increasing concentrations of B19 in U-2 OS cells infected with HSV-1 strain F (MOI 1). MW: molecular weight (Marker VI, Applichem). ICP4 bands were quantified with respect to alpha-tubulin (housekeeping) levels in each lane. Mean average values of two independent experiments.

\section{Discussion}

We have previously shown that viral G4s form massively during HSV-1 replication in cells and that they are present in long repeated region of the HSV-1 genome and in promoters of IE genes (Artusi et al., 2015, 2016; Frasson et al., 2019). The dynamics of cellular and viral G4s in cells have been reported to be regulated by proteins. For instance, folding of one of the best studied G4s, located in the c-myc promoter, is regulated by the interaction with different proteins (Brooks and Hurley, 2009); similarly, viral G4s that form in the promoter of the HIV-1 integrated genome are processed by cellular proteins that stabilize and unfold them (Scalabrin et al., 2017b; Tosoni et al., 2015). Given these premises, we investigated whether HSV-1 G4s were also processed by proteins during the productive viral life cycle. Besides the two cellular proteins hnRNPA1L2 and NCL already reported to interact with G4s (González and Hurley, 2010; Lago et al., 2017; 
Paramasivam et al., 2009; Tosoni et al., 2015), we identified for the first time viral proteins able to interact with G4s: these are all involved in some steps of DNA processing. The total number of proteins that selectively interacted with G4s did not increase during infection and, even though they slightly changed in composition, the main proteins recovered at the G4s did not vary along viral replication, supporting the G4specific role of these proteins. In contrast, composition of the viral proteins that were reported to interact with the whole viral genome reflected the differential protein production during the viral life cycle (Dembowski and DeLuca, 2018).

ICP4 is a key factor in transcription regulation and viral growth (Dembowski and DeLuca, 2015, 2018; Grondin et al., 2000; Kuddus et al., 1995). Up to now, ICP4 had been reported to act as a positive regulator of transcription (Beard et al., 1986) by recognizing an asymmetric DNA consensus sequence, as well as DNA sequences that deviate from the consensus binding site (Tunnicliffe et al., 2017). Our findings indicate that ICP4 exerts its activity also via G4 recognition, as ICP4/viral G4s direct interaction was clearly visible in infected cells throughout the viral cycle.

G4 folding inhibits DNA and RNA polymerases both in vitro and in cell (Spiegel et al., 2020). In fact, when G4s form in gene promoter regions, they typically inhibit gene transcription (Perrone et al., 2013; Xu et al., 2017). However, the presence of $G 4 s$ at gene promoters was shown to be tightly associated with transcription (Hänsel-Hertsch et al., 2016). Our work may help explaining this apparent discrepancy on how G4s are linked to active transcription in cells. ICP4, one of the most important transcription factors in HSV-1 gene expression (Dembowski and DeLuca, 2015; Grondin et al., 2000), strongly binds to G4s in cells and promotes transcription by unfolding the $\mathrm{G} 4$ and promoting assembly of the transcription machinery (Grondin et al., 2000). In line with this evidence, we have recently demonstrated that the HSV-1 IE promoters contain multiple conserved G4s, the large majority of which folds into parallel G4s, and ICP4 regulates transcription of at least two of these IE genes (ICP0 and ICP4 itself) (Frasson et al., 2019). Thus, ICP4 preference for the parallel G4s could be a mechanism for the preferred recognition of promoter-located viral G4s over the large number of G4s that are normally present in the cell (Hänsel-Hertsch et al., 2016). The only natural protein reported to unfold G4s while discriminating among G4 structures is DHX36, a human helicase (Chen et al., 2018), three proteins were shown to preferentially bind parallel G4s (Carle et al., 2016; Roach et al., 2020; Schierer and Henderson, 1994), while all other G4-interacting proteins up to date have been reported to discriminate the folded and unfolded structures, rather than different G4 topologies (Cogoi et al., 2014; Lago et al., 2017). Recruitment of transcription factors at the G4s may be a mechanism also exploited by the cell: in fact, cellular transcription factors, such as the human mitochondrial transcription factor A and SP1, have been reported to interact with G4s in cells and in vitro, respectively (Lyonnais et al., 2017; Perrone et al., 2017; Raiber et al., 2012).

Based on the data collected here, we propose G4s as recognition motifs at the promoter level. When a protein with unfolding properties recognizes them and recruits the transcription machinery, such as in the case of ICP4, strong transcription is induced; when a protein stabilizes the G4, induction or repression of transcription can occur, based on the activity of the other proteins that are recruited at the site, if any. Considering that G4-containing promoters corresponded principally to high transcriptional levels in a genome-wide study (Hänsel-Hertsch et al., 2016), induction of transcription may be the main role of G4s at gene promoters. In addition, since, except for helicases and few other proteins (Budhathoki et al., 2015; Butovskaya et al., 2019; Chen et al., 2018; David et al., 2019; Gueddouda et al., 2017; Paramasivam et al., 
2009; Sauer and Paeschke, 2017; Scalabrin et al., 2017b; Voter et al., 2018; Wu et al., 2019), the vast majority of G4 binding protein stabilizes G4s (Brázda et al., 2014; Schwindt and Paeschke, 2018; Tosoni et al., 2015), recruitment of transcription factors by G4-interacting proteins may be the most common mechanism.

Our data indicate that ICP4 can also recognize cellular parallel G4s, therefore suggesting a role of HSV-1 in human gene expression regulation. In fact, ICP4 was reported to upregulate the vascular endothelial growth factor (VEGF), through binding of ICP4 to the three tracts of GC-rich sequences in the proximal human VEGF promoter (Wuest et al., 2011). The authors did not describe the specific ICP4-VEGF interaction but hinted that formation of G4s at that specific region of the VEGF promoter could be targeted by G4 ligands to suppress transcription, to be exploited as anticancer strategy (Sun et al., 2008). Notably, the G4 embedded in the VEGF promoter displays a parallel structure. These data altogether indicate that the G4-mediated mechanism of transcription regulation is conserved and exploited by both eukaryotic cells and viruses and suggest that cross regulation may occur via this mechanism.

We have previously indicated the possible use of G4 ligands as antiviral compounds. Indeed, B19 and other G4 ligands were proven to hinder HSV-1 viral replication without affecting HSV-1 entry (Artusi et al., 2015; Callegaro et al., 2017). Here we further revealed that B19 strongly affects the expression of ICP4 protein acting on its own promoter, thus hampering all subsequent ICP4 transcriptional activities. Thus, the described data may offer a new direction for antiviral design. Up to date, only polymerase inhibitors are available against HSV-1 (Poole and James, 2018). The rising of resistant HSV-1 strains that may be extremely dangerous especially in transplant and immunocompromised patients (Jiang et al., 2016) urges the discovery of new antivirals with a different mechanism of action. We propose that selective anti-ICP4 promoter G4-ligands would hamper the viral cycle at a very early stage, preventing neuronal damage linked to HSV-1 infection.

\section{Acknowledgments}

This work was supported by the University of Padua (PRID/SID 2018).

\section{Author Contributions}

Conceptualization, I.F. and S.N.R.; Methodology, I.F. and M.N.; Investigation, I.F., P.S., M.N. and S.L.; Writing - Original Draft, I.F.; Writing - Review \& Editing, S.N.R.; Funding Acquisition, S.N.R.

\section{Declaration of Interests}

The authors declare no competing interests.

\section{References}

Agrawal, P., Lin, C., Mathad, R.I., Carver, M., and Yang, D. (2014). The Major G-Quadruplex Formed in the Human BCL-2 Proximal Promoter Adopts a Parallel Structure with a 13-nt Loop in K ${ }^{+}$Solution. J. Am. Chem. Soc. 136, 1750-1753.

Artusi, S., Nadai, M., Perrone, R., Biasolo, M.A., Palù, G., Flamand, L., Calistri, A., and Richter, S.N. (2015). The Herpes Simplex Virus-1 genome contains multiple clusters of repeated G-quadruplex: Implications for the antiviral activity of a G-quadruplex ligand. Antiviral Res. 118, 123-131. 
Artusi, S., Perrone, R., Lago, S., Raffa, P., Di lorio, E., Palù, G., and Richter, S.N. (2016). Visualization of DNA G-quadruplexes in herpes simplex virus 1-infected cells. Nucleic Acids Res. 44, 10343-10353.

Asamitsu, S., Obata, S., Yu, Z., Bando, T., and Sugiyama, H. (2019). Recent Progress of Targeted GQuadruplex-Preferred Ligands Toward Cancer Therapy. Molecules 24, 429.

Bartas, M., Cutová, M., Brázda, V., Kaura, P., Št’Astný, J., Kolomazník, J., Coufal, J., Goswami, P., Červeň, J., and Pečinka, P. (2019). The presence and localization of G-Quadruplex forming sequences in the domain of bacteria. Molecules 24.

Beard, P., Faber, S., Wilcox, K.W., and Pizer, L.I. (1986). Herpes simplex virus immediate early infected-cell polypeptide 4 binds to DNA and promotes transcription. Proc. Natl. Acad. Sci. 83, 4016-4020.

Bedrat, A., Lacroix, L., and Mergny, J.L. (2016). Re-evaluation of G-quadruplex propensity with G4Hunter. Nucleic Acids Res. 44, 1746-1759.

Biffi, G., Tannahill, D., McCafferty, J., and Balasubramanian, S. (2013). Quantitative visualization of DNA Gquadruplex structures in human cells. Nat. Chem. 5, 182-186.

Biswas, B., Kandpal, M., Jauhari, U.K., and Vivekanandan, P. (2016). Genome-wide analysis of Gquadruplexes in herpesvirus genomes. BMC Genomics 17, 949.

Brázda, V., Hároníková, L., Liao, J., and Fojta, M. (2014). DNA and RNA Quadruplex-Binding Proteins. Int. J. Mol. Sci. 15, 17493-17517.

Brooks, T.A., and Hurley, L.H. (2009). The role of supercoiling in transcriptional control of MYC and its importance in molecular therapeutics. Nat. Rev. Cancer 9, 849-861.

Budhathoki, J.B., Stafford, E.J., Yodh, J.G., and Balci, H. (2015). ATP-dependent G-quadruplex unfolding by Bloom helicase exhibits low processivity. Nucleic Acids Res. 43, 5961-5970.

Burger, A.M., Dai, F., Schultes, C.M., Reszka, A.P., Moore, M.J., Double, J.A., and Neidle, S. (2005). The Gquadruplex-interactive molecule BRACO-19 inhibits tumor growth, consistent with telomere targeting and interference with telomerase function. Cancer Res. 65, 1489-1496.

Butovskaya, E., Heddi, B., Bakalar, B., Richter, S.N., and Phan, A.T. (2018). Major G-Quadruplex Form of HIV-1 LTR Reveals a (3 + 1) Folding Topology Containing a Stem-Loop. J. Am. Chem. Soc. 140, 1365413662.

Butovskaya, E., Soldà, P., Scalabrin, M., Nadai, M., and Richter, S.N. (2019). HIV-1 Nucleocapsid Protein Unfolds Stable RNA G-Quadruplexes in the Viral Genome and Is Inhibited by G-Quadruplex Ligands. ACS Infect. Dis.

Calabrese, D.R., Chen, X., Leon, E.C., Gaikwad, S.M., Phyo, Z., Hewitt, W.M., Alden, S., Hilimire, T.A., He, F., Michalowski, A.M., et al. (2018). Chemical and structural studies provide a mechanistic basis for recognition of the MYC G-quadruplex. Nat. Commun. 9, 4229.

Callegaro, S., Perrone, R., Scalabrin, M., Doria, F., Palù, G., and Richter, S.N. (2017). A core extended naphtalene diimide G-quadruplex ligand potently inhibits herpes simplex virus 1 replication. Sci. Rep. 7.

Carle, C.M., Zaher, H.S., and Chalker, D.L. (2016). A Parallel G Quadruplex-Binding Protein Regulates the Boundaries of DNA Elimination Events of Tetrahymena thermophila. PLOS Genet. 12, e1005842.

Chen, M.C., Tippana, R., Demeshkina, N.A., Murat, P., Balasubramanian, S., Myong, S., and Ferré-D'amaré, A.R. (2018). Structural basis of G-quadruplex unfolding by the DEAH/RHA helicase DHX36. Nature 558, 465-483.

Cogoi, S., Shchekotikhin, A.E., and Xodo, L.E. (2014). HRAS is silenced by two neighboring G-quadruplexes 
and activated by MAZ, a zinc-finger transcription factor with DNA unfolding property. Nucleic Acids Res. 42, 8379-8388.

Cohen, E.M., and Kobiler, O. (2016). Gene Expression Correlates with the Number of Herpes Viral Genomes Initiating Infection in Single Cells. PLoS Pathog. 12.

Collie, G.W., Haider, S.M., Neidle, S., and Parkinson, G.N. (2010). A crystallographic and modelling study of a human telomeric RNA (TERRA) quadruplex. Nucleic Acids Res. 38, 5569-5580.

David, A.P., Pipier, A., Pascutti, F., Binolfi, A., J. Weiner, A.M., Challier, E., Heckel, S., Calsou, P., Gomez, D., Calcaterra, N.B., et al. (2019). CNBP controls transcription by unfolding DNA G-quadruplex structures. Nucleic Acids Res.

De Nicola, B., Lech, C.J., Heddi, B., Regmi, S., Frasson, I., Perrone, R., Richter, S.N., and Phan, A.T. (2016). Structure and possible function of a G-quadruplex in the long terminal repeat of the proviral HIV-1 genome. Nucleic Acids Res. 44, 6442-6451.

del Villar-Guerra, R., Trent, J.O., and Chaires, J.B. (2018). G-Quadruplex Secondary Structure Obtained from Circular Dichroism Spectroscopy. Angew. Chemie Int. Ed. 57, 7171-7175.

Dembowski, J.A., and DeLuca, N.A. (2015). Selective Recruitment of Nuclear Factors to Productively Replicating Herpes Simplex Virus Genomes. PLOS Pathog. 11, e1004939.

Dembowski, J.A., and DeLuca, N.A. (2018). Temporal Viral Genome-Protein Interactions Define Distinct Stages of Productive Herpesviral Infection. MBio 9.

Didonato, J.A., and Muller, M.T. (1989). DNA Binding and Gene Regulation by the Herpes Simplex Virus Type 1 Protein ICP4 and Involvement of the TATA Element.

DiDonato, J.A., Spitzner, J.R., and Muller, M.T. (1991). A predictive model for DNA recognition by the herpes simplex virus protein ICP4. J. Mol. Biol. 219, 451-470.

Domon, B., and Aebersold, R. (2006). Mass spectrometry and protein analysis. Science (80-. ). 312, 212217.

Everett, R.D., and Murray, J. (2005). ND10 components relocate to sites associated with herpes simplex virus type 1 nucleoprotein complexes during virus infection. J. Virol. 79, 5078-5089.

Everett, R.D., Sourvinos, G., and Orr, A. (2003). Recruitment of herpes simplex virus type 1 transcriptional regulatory protein ICP4 into foci juxtaposed to ND10 in live, infected cells. J. Virol. 77, 3680-3689.

Everett, R.D., Murray, J., Orr, A., and Preston, C.M. (2007). Herpes Simplex Virus Type 1 Genomes Are Associated with ND10 Nuclear Substructures in Quiescently Infected Human Fibroblasts. J. Virol. 81, 10991-11004.

Frasson, I., Nadai, M., and Richter, S.N. (2019). Conserved G-Quadruplexes Regulate the Immediate Early Promoters of Human Alphaherpesviruses. Molecules 24, 2375.

Fredriksson, S., Gullberg, M., Jarvius, J., Olsson, C., Pietras, K., Gústafsdóttir, S.M., Östman, A., and Landegren, U. (2002). Protein detection using proximity-dependent DNA ligation assays. Nat. Biotechnol. 20, 473-477.

González, V., and Hurley, L.H. (2010). The C-terminus of nucleolin promotes the formation of the C-MYC Gquadruplex and inhibits c-MYC promoter activity. Biochemistry 49, 9706-9714.

Gray, L.T., Vallur, A.C., Eddy, J., and Maizels, N. (2014). G quadruplexes are genomewide targets of transcriptional helicases XPB and XPD. Nat. Chem. Biol. 10, 313-318.

Grondin, B., DeLuca, N., DeLuca, N.A., Gu, B., and DeLuca, N.A. (2000). Herpes simplex virus type 1 ICP4 
promotes transcription preinitiation complex formation by enhancing the binding of TFIID to DNA. J. Virol. 74, $11504-11510$.

Gu, B., Kuddus, R., and DeLuca, N.A. (1995). Repression of activator-mediated transcription by herpes simplex virus ICP4 via a mechanism involving interactions with the basal transcription factors TATA-binding protein and TFIIB. Mol. Cell. Biol. 15, 3618-3626.

Gueddouda, N.M., Mendoza, O., Gomez, D., Bourdoncle, A., and Mergny, J.L. (2017). G-quadruplexes unfolding by RHAU helicase. Biochim. Biophys. Acta - Gen. Subj. 1861, 1382-1388.

Haeusler, A.R., Donnelly, C.J., Periz, G., Simko, E.A.J., Shaw, P.G., Kim, M.S., Maragakis, N.J., Troncoso, J.C., Pandey, A., Sattler, R., et al. (2014). C9orf72 nucleotide repeat structures initiate molecular cascades of disease. Nature 507, 195-200.

Hänsel-Hertsch, R., Beraldi, D., Lensing, S. V, Marsico, G., Zyner, K., Parry, A., Di Antonio, M., Pike, J., Kimura, H., Narita, M., et al. (2016). G-quadruplex structures mark human regulatory chromatin. Nat. Genet. 48, 1267-1272.

Hänsel-Hertsch, R., Di Antonio, M., and Balasubramanian, S. (2017). DNA G-quadruplexes in the human genome: Detection, functions and therapeutic potential. Nat. Rev. Mol. Cell Biol. 18, 279-284.

Heddi, B., and Phan, A.T. (2011). Structure of Human Telomeric DNA in Crowded Solution. J. Am. Chem. Soc. 133, 9824-9833.

Heming, J.D., Conway, J.F., and Homa, F.L. (2017). Herpesvirus Capsid Assembly and DNA Packaging. Adv. Anat. Embryol. Cell Biol. 223, 119-142.

Hoffman, E.A., Frey, B.L., Smith, L.M., and Auble, D.T. (2015). Formaldehyde crosslinking: a tool for the study of chromatin complexes. J. Biol. Chem. 290, 26404-26411.

Imbalzano, A.N., Shepard, A.A., and DeLuca, N.A. (1990). Functional relevance of specific interactions between herpes simplex virus type 1 ICP 4 and sequences from the promoter-regulatory domain of the viral thymidine kinase gene. J. Virol. 64, 2620-2631.

Jiang, Y.-C., Feng, H., Lin, Y.-C., and Guo, X.-R. (2016). New strategies against drug resistance to herpes simplex virus. Int. J. Oral Sci. 8, 1-6.

Jin, B., Zhang, X., Zheng, W., Liu, X., Qi, C., Wang, F., and Shangguan, D. (2014). Fluorescence light-up probe for parallel G-quadruplexes. Anal. Chem. 86, 943-952.

Koujah, L., Suryawanshi, R.K., and Shukla, D. (2019). Pathological processes activated by herpes simplex virus-1 (HSV-1) infection in the cornea. Cell. Mol. Life Sci. 76, 405-419.

Kuddus, R., Gu, B., and DeLuca, N.A. (1995). Relationship between TATA-binding protein and herpes simplex virus type 1 ICP4 DNA-binding sites in complex formation and repression of transcription. J. Virol. 69, 5568-5575.

Lago, S., Tosoni, E., Nadai, M., Palumbo, M., and Richter, S.N. (2017). The cellular protein nucleolin preferentially binds long-looped G-quadruplex nucleic acids. Biochim. Biophys. Acta - Gen. Subj. 1861, 1371-1381.

Lavezzo, E., Berselli, M., Frasson, I., Perrone, R., Palù, G., Brazzale, A.R., Richter, S.N., and Toppo, S. (2018). G-quadruplex forming sequences in the genome of all known human viruses: A comprehensive guide. PLoS Comput. Biol. 14.

Liu, H.Y., Zhao, Q., Zhang, T.P., Wu, Y., Xiong, Y.X., Wang, S.K., Ge, Y.L., He, J.H., Lv, P., Ou, T.M., et al. (2016). Conformation Selective Antibody Enables Genome Profiling and Leads to Discovery of Parallel G- 
Quadruplex in Human Telomeres. Cell Chem. Biol. 23, 1261-1270.

Lyonnais, S., Tarrés-Solé, A., Rubio-Cosials, A., Cuppari, A., Brito, R., Jaumot, J., Gargallo, R., Vilaseca, M., Silva, C., Granzhan, A., et al. (2017). The human mitochondrial transcription factor A is a versatile Gquadruplex binding protein. Sci. Rep. 7, 43992.

Marsico, G., Chambers, V.S., Sahakyan, A.B., McCauley, P., Boutell, J.M., Antonio, M. Di, and Balasubramanian, S. (2019). Whole genome experimental maps of DNA G-quadruplexes in multiple species. Nucleic Acids Res. 47, 3862-3874.

Mathad, R.I., Hatzakis, E., Dai, J., and Yang, D. (2011). c-MYC promoter G-quadruplex formed at the 5'-end of NHE III1 element: insights into biological relevance and parallel-stranded G-quadruplex stability. Nucleic Acids Res. 39, 9023-9033.

Monsen, R.C., DeLeeuw, L., Dean, W.L., Gray, R.D., Sabo, T.M., Chakravarthy, S., Chaires, J.B., and Trent, J.O. (2020). The hTERT core promoter forms three parallel G-quadruplexes. Nucleic Acids Res. 48, 57205734.

Nadai, M., Doria, F., Scalabrin, M., Pirota, V., Grande, V., Bergamaschi, G., Amendola, V., Winnerdy, F.R., Phan, A.T., Richter, S.N., et al. (2018). A Catalytic and Selective Scissoring Molecular Tool for Quadruplex Nucleic Acids. J. Am. Chem. Soc. 140, 14528-14532.

Paramasivam, M., Membrino, A., Cogoi, S., Fukuda, H., Nakagama, H., and Xodo, L.E. (2009). Protein hnRNP A1 and its derivative Up1 unfold quadruplex DNA in the human KRAS promoter: implications for transcription. Nucleic Acids Res. 37, 2841-2853.

Parkinson, G.N., Lee, M.P.H., and Neidle, S. (2002). Crystal structure of parallel quadruplexes from human telomeric DNA. Nature 417, 876-880.

Perrone, R., Nadai, M., Frasson, I., Poe, J.A., Butovskaya, E., Smithgall, T.E., Palumbo, M., Paluì, G., and Richter, S.N. (2013). A Dynamic G-quadruplex region regulates the HIV-1 Long terminal repeat promoter. J. Med. Chem. 56, 6521-6530.

Perrone, R., Doria, F., Butovskaya, E., Frasson, I., Botti, S., Scalabrin, M., Lago, S., Grande, V., Nadai, M., Freccero, M., et al. (2015). Synthesis, Binding and Antiviral Properties of Potent Core-Extended Naphthalene Diimides Targeting the HIV-1 Long Terminal Repeat Promoter G-Quadruplexes. J. Med. Chem. 58, 96399652.

Perrone, R., Lavezzo, E., Palù, G., and Richter, S.N. (2017). Conserved presence of G-quadruplex forming sequences in the Long Terminal Repeat Promoter of Lentiviruses. Sci. Rep. 7.

Poole, C.L., and James, S.H. (2018). Antiviral Therapies for Herpesviruses: Current Agents and New Directions. Clin. Ther. 40, 1282-1298.

Prorok, P., Artufel, M., Aze, A., Coulombe, P., Peiffer, I., Lacroix, L., Guédin, A., Mergny, J.L., Damaschke, J., Schepers, A., et al. (2019). Involvement of G-quadruplex regions in mammalian replication origin activity. Nat. Commun. 10, 1-16.

Raiber, E.-A., Kranaster, R., Lam, E., Nikan, M., and Balasubramanian, S. (2012). A non-canonical DNA structure is a binding motif for the transcription factor SP1 in vitro. Nucleic Acids Res. 40, 1499-1508.

Roach, R.J., Garavís, M., González, C., Jameson, G.B., Filichev, V. V, and Hale, T.K. (2020).

Heterochromatin protein $1 \alpha$ interacts with parallel RNA and DNA G-quadruplexes. Nucleic Acids Res. 48, 682-693.

Sahakyan, A.B., Chambers, V.S., Marsico, G., Santner, T., Di Antonio, M., and Balasubramanian, S. (2017). 
Machine learning model for sequence-driven DNA G-quadruplex formation. Sci. Rep. 7, 14535.

Sauer, M., and Paeschke, K. (2017). G-quadruplex unwinding helicases and their function in vivo. Biochem. Soc. Trans. 45, 1173-1182.

Scalabrin, M., Palumbo, M., and Richter, S.N. (2017a). Highly Improved Electrospray lonization-Mass Spectrometry Detection of G-Quadruplex-Folded Oligonucleotides and Their Complexes with Small Molecules. Anal. Chem. 89, 8632-8637.

Scalabrin, M., Frasson, I., Ruggiero, E., Perrone, R., Tosoni, E., Lago, S., Tassinari, M., Palù, G., and Richter, S.N. (2017b). The cellular protein hnRNP A2/B1 enhances HIV-1 transcription by unfolding LTR promoter G-quadruplexes. Sci. Rep. 7.

Schierer, T., and Henderson, E. (1994). A Protein from Tetrahymena thermophila That Specifically Binds Parallel-Stranded G4-DNA. Biochemistry 33, 2240-2246.

Schwindt, E., and Paeschke, K. (2018). Mms1 is an assistant for regulating G-quadruplex DNA structures. Curr. Genet. 64, 535-540.

Shevchenko, A., Tomas, H., Havlis, J., Olsen, J. V, and Mann, M. (2006). In-gel digestion for mass spectrometric characterization of proteins and proteomes. Nat. Protoc. 1, 2856-2860.

Spiegel, J., Adhikari, S., and Balasubramanian, S. (2020). The Structure and Function of DNA GQuadruplexes. Trends Chem. 2, 123-136.

Suk, H., and Knipe, D.M. (2015). Proteomic analysis of the herpes simplex virus 1 virion protein 16 transactivator protein in infected cells. Proteomics 15, 1957-1967.

Sun, D., Liu, W.J., Guo, K., Rusche, J.J., Ebbinghaus, S., Gokhale, V., Hurley, L.H., and Daekyu Sun, WeiJun Liu, Kexiao Guo, Jadrian J. Rusche, Scot Ebbinghaus, Vijay Gokhale, L.H.H. (2008). The proximal promoter region of the human vascular endothelial growth factor gene has a G-quadruplex structure that can be targeted by G-quadruplex-interactive agents. Mol. Cancer Ther. 7, 880-889.

Tassinari, M., Zuffo, M., Nadai, M., Pirota, V., Sevilla Montalvo, A.C., Doria, F., Freccero, M., and Richter, S.N. (2020). Selective targeting of mutually exclusive DNA G-quadruplexes: HIV-1 LTR as paradigmatic model. Nucleic Acids Res. 48, 4627-4642.

Tateishi-Karimata, H., and Sugimoto, N. (2020). Chemical biology of non-canonical structures of nucleic acids for therapeutic applications. Chem. Commun. 56, 2379-2390.

Tedder, D.G., Everett, R.D., Wilcox, K.W., Beard, P., and Pizer, L.I. (1989). ICP4-binding sites in the promoter and coding regions of the herpes simplex virus $\mathrm{gD}$ gene contribute to activation of in vitro transcription by ICP4. J. Virol. 63, 2510-2520.

Tosoni, E., Frasson, I., Scalabrin, M., Perrone, R., Butovskaya, E., Nadai, M., Palù, G., Fabris, D., and Richter, S.N. (2015). Nucleolin stabilizes G-quadruplex structures folded by the LTR promoter and silences HIV-1 viral transcription. Nucleic Acids Res. 43, 8884-8897.

Tunnicliffe, R.B., Lockhart-Cairns, M.P., Levy, C., Mould, A.P., Jowitt, T.A., Sito, H., Baldock, C., SandriGoldin, R.M., and Golovanov, A.P. (2017). The herpes viral transcription factor ICP4 forms a novel DNA recognition complex. Nucleic Acids Res. 45, 8064-8078.

Vorličková, M., Kejnovská, I., Sagi, J., Renčiuk, D., Bednářová, K., Motlová, J., and Kypr, J. (2012). Circular dichroism and guanine quadruplexes. Methods 57, 64-75.

Voter, A.F., Qiu, Y., Tippana, R., Myong, S., and Keck, J.L. (2018). A guanine-flipping and sequestration mechanism for G-quadruplex unwinding by RecQ helicases. Nat. Commun. 9, 4201. 
Wagner, L.M., and DeLuca, N.A. (2013). Temporal Association of Herpes Simplex Virus ICP4 with Cellular Complexes Functioning at Multiple Steps in PollI Transcription. PLoS One 8, e78242.

Wang, Y., Yang, J., Wild, A.T., Wu, W.H., Shah, R., Danussi, C., Riggins, G.J., Kannan, K., Sulman, E.P., Chan, T.A., et al. (2019). G-quadruplex DNA drives genomic instability and represents a targetable molecular abnormality in ATRX-deficient malignant glioma. Nat. Commun. 10.

Wu, G., Xing, Z., Tran, E.J., and Yang, D. (2019). DDX5 helicase resolves G-quadruplex and is involved in MYC gene transcriptional activation. Proc. Natl. Acad. Sci. U. S. A. 116, 20453-20461.

Wuest, T., Zheng, M., Efstathiou, S., Halford, W.P., and Carr, D.J.J. (2011). The herpes simplex virus-1 transactivator infected cell protein-4 drives VEGF-A dependent neovascularization. PLoS Pathog. 7, e1002278.

Xiao, W., Pizer, L.I., and Wilcox, K.W. (1997). Identification of a promoter-specific transactivation domain in the herpes simplex virus regulatory protein ICP4. J. Virol. 71, 1757-1765.

Xu, H., Di Antonio, M., McKinney, S., Mathew, V., Ho, B., O'Neil, N.J., Santos, N. Dos, Silvester, J., Wei, V., Garcia, J., et al. (2017). CX-5461 is a DNA G-quadruplex stabilizer with selective lethality in BRCA1/2 deficient tumours. Nat. Commun. 8, 14432.

Yang, D., and Hurley, L. (2006). Structure of the biologically relevant g-quadruplex in the c-MYC promoter. Nucleosides, Nucleotides and Nucleic Acids 25, 951-968.

\section{Materials and methods}

\section{Cell lines and viruses}

Human bone osteosarcoma cells (U-2 OS, European Collection of Authenticated Cell Cultures (ECACC), purchased from Sigma Aldrich, Milan, Italy) were maintained in Dulbecco's Modified Eagle Medium (DMEM, Gibco, Life Technologies, Monza, Italy) supplemented with 10\% heat-inactivated and filtrated foetal bovine serum (FBS, Gibco, Life Technologies, Monza, Italy). Cells were maintained in a humidified incubator set at $37^{\circ} \mathrm{C}$ with $5 \% \mathrm{CO}_{2}$. HSV-1 strain F (GenBank: GU734771) was propagated on U2-OS cells. Viral stocks were prepared in 3\% FBS Dulbecco's modified Eagle's media (Gibco, ThermoFisher Scientific, Monza, Italy).

\section{Circular Dichroism Spectroscopy}

DNA oligonucleotides were diluted to a final concentration $(4 \mu \mathrm{M})$ in potassium phosphate buffer $(\mathrm{PB}, 20$ $\mathrm{mM}, \mathrm{pH} 7.4, \mathrm{KCl} 2-80 \mathrm{mM}$ ). All samples were annealed at $95{ }^{\circ} \mathrm{C}$ for $5 \mathrm{~min}$ and gradually cooled to room temperature. CD spectra were recorded on a Chirascan-Plus (Applied Photophysics, Leatherhead, UK) equipped with a Peltier temperature controller using a quartz cell of $5 \mathrm{~mm}$ optical path length, over a wavelength range of $230-320 \mathrm{~nm}$. For the determination of $\mathrm{T}_{\mathrm{m}}$, spectra were recorded over a temperature range of $20-90{ }^{\circ} \mathrm{C}$, with temperature increase of $5{ }^{\circ} \mathrm{C}$. The reported spectra are baseline-corrected for signal contributions due to the buffer. Observed ellipticities were converted to mean residue ellipticity $(\theta)=\operatorname{deg} \times$ $\mathrm{cm} 2 \times \mathrm{dmol}-1$ (mol ellip). Tm values were calculated according to the van't Hoff equation, applied for a twostate transition from a folded to unfolded state, assuming that the heat capacity of the folded and unfolded states are equal. 


\section{Nuclear proteins extraction from HSV-1 infected cells}

U-2 OS cells $\left(5.3 \times 10^{6}\right)$ were plated in $150 \mathrm{~cm}^{2}$ cell culture flasks in DMEM supplemented with $10 \%$ FBS. $24 \mathrm{~h}$ after seeding, the medium was removed and cells were infected with HSV-1 strain $\mathrm{F}$ (MOI of 2) in serum-free medium. After $1 \mathrm{~h}$ at $37^{\circ} \mathrm{C}$, cells were washed with $1 \mathrm{X}$ PBS and fresh complete medium was restored. At different times post-infection ( 8 and 16 h.p.i.), cells were scraped off and centrifuged at 1250 rpm for $5 \mathrm{~min}$ at $4^{\circ} \mathrm{C}$. Pellets were processed according to the B protocol of the NXTRACT kit (CelLytic ${ }^{\text {TM }}$ NuCLEAR ${ }^{\mathrm{TM}} \quad$ Sigma-Aldrich, Milan, Italy https://www.sigmaaldrich.com/content/dam/sigmaaldrich/docs/Sigma/Bulletin/nxtractbul.pdf), in order to obtain native nuclear proteins. Proteins extracts were quantified using the Pierce ${ }^{\mathrm{TM}}$ BCA Protein Assay kit (ThermoFisher Scientific, Monza, Italy) and stored in aliquots at $-80^{\circ} \mathrm{C}$ until use.

\section{Pull-down assay}

The pull-down assay was performed in order to identify HSV-1 G4-protein interactions. Dynabeads $\rightarrow \mathrm{M}-280$ Streptavidin (Life Technologies, Monza, Italy) were used to immobilize the biotinylated oligonucleotides, according to the manufacturer's protocol. Briefly, $50 \mu \mathrm{L}$ of beads were incubated with $300 \mathrm{pmol}$ of biotinylated oligonucleotides ( $15 \mathrm{~min}$ at room temperature, RT). Control samples without oligonucleotides were included in each experiment in order to monitor the nonspecific binding to the beads. After three washes $(50 \mathrm{mM}$ Tris- $\mathrm{HCl}, 150 \mathrm{mM} \mathrm{NaCl})$, nuclear proteins extracts $(5 \mu \mathrm{g})$ were incubated with the immobilized DNA fragments and maintained at $4^{\circ} \mathrm{C}$ for $2 \mathrm{~h}$. To wash out nonspecific binders, samples were rinsed three times in $20 \mathrm{mM}$ phosphate buffer $(\mathrm{PB})$ and $150 \mathrm{mM} \mathrm{KCl}$. Two proteins elution were performed: the first in $\mathrm{NaCl} 2 \mathrm{M}(10 \mathrm{~min}$ ) and the second in 2x Laemmli buffer (4\% SDS, 80\% glycerol, $120 \mathrm{mM}$ Tris- $\mathrm{HCl}$ $\mathrm{pH}$ 6.8, $200 \mathrm{mM}$ DTT, $0.02 \%$ bromophenol blue, $10 \mathrm{~min}$ ). Eluted proteins were denatured at $95^{\circ} \mathrm{C}$ and separated on SDS-PAGE. Gels were stained overnight in colloidal Coomassie staining $(0.02 \% \mathrm{w} / \mathrm{v}$ CBB G$250,5 \% \mathrm{w} / \mathrm{v}$ aluminum sulfate-(14-18)-hydrate, $10 \% \mathrm{v} / \mathrm{v}$ ethanol, $2 \% \mathrm{~g} / \mathrm{v}$ orthophosphoric acid) and unstained in $10 \%$ ethanol and $2 \%$ orthophosphoric acid for at least 30 minutes. Destained gels (10\% acetic acid in milliQ water) were cut into bands of approximately $0.5 \mathrm{~cm}$ per side. Each band was further fragmented and subjected to tryptic digestion.

\section{Bands digestion and LC-MS protein identification}

Bands were treated according to established in-gel digestion protocols (Shevchenko et al., 2006). Briefly, they were first bleached with $50 \% \mathrm{CH}_{3} \mathrm{OH}$ and $2.5 \%$ acetic acid and dehydrated with $\mathrm{CH}_{3} \mathrm{CN}$. Peptides were then reduced with $50 \mu \mathrm{L}$ of DTT (10 mM in $100 \mathrm{mM} \mathrm{NH}_{4} \mathrm{HCO}_{3}$ ) for 30 min at RT. After DTT removal, peptides were treated with $50 \mu \mathrm{L}$ of iodoacetamide ( $50 \mathrm{mM}$ in $100 \mathrm{mM} \mathrm{NH}_{4} \mathrm{HCO}_{3}$ ) for $30 \mathrm{~min}$ at $\mathrm{RT}$ in the dark in order to alkylate cysteine residues. Bands were washed with $100 \mathrm{mM} \mathrm{NH} \mathrm{HCO}_{3}$ and dehydrated with $\mathrm{CH}_{3} \mathrm{CN}$ twice. After that, $1 \mu \mathrm{g}$ aliquot of MS-grade trypsin (ThermoFisher Scientific, Monza, Italy) in $50 \mu \mathrm{L}$ of $50 \mathrm{mM}$ $\mathrm{NH}_{4} \mathrm{HCO}_{3}$ was added to each dehydrated bands and incubated on ice for $30 \mathrm{~min}$. The excess of trypsin was eliminated and substituted with $40 \mu \mathrm{L}$ of $50 \mathrm{mM} \mathrm{NH}_{4} \mathrm{HCO}_{3}$. Samples were then incubated overnight at $37^{\circ} \mathrm{C}$. Peptides were extracted twice with $5 \% \mathrm{HCOOH}$ and two more times with $50 \% \mathrm{CH}_{3} \mathrm{CN}, 5 \% \mathrm{HCOOH}$. Samples were further concentrated in SpeedVac (Hetovac VR-1, Heto Lab Equipment, Denmark) to $1 \mu \mathrm{L}$ and resuspended in $20 \mu \mathrm{L}$ of $1 \% \mathrm{HCOOH}$. Peptides were then analysed by liquid chromatography mass 
spectrometry (LC-MS) using an Agilent 1290 Infinity HPLC (Agilent Technologies, Santa Clara, CA, USA) connected to a Xevo G2-XS QTof mass spectrometer (Waters, Milford, MS, USA) from Micromass (Manchester, UK). A full scan mode and a high energy $\mathrm{MS}^{\mathrm{e}}$ scan mode were used. Parent ions having the charge state $4^{+}, 3^{+}$and $2^{+}$and signals more intense than 200 counts and the related $\mathrm{MS}^{\mathrm{e}}$ fragments ion signals more intense than 50 counts were subjected to the Mascot Database Search to identify their parent protein.

\section{ICP4 purification by immunoprecipitation}

ICP4 was purified by means of the Cross-link IP Kit (ThermoFisher Scientific, Monza, Italy), according to manufacturer instructions. Briefly, $10 \mu \mathrm{g}$ of anti ICP4 antibody (mouse monoclonal H943, Santa Cruz Biotechnology, Dallas, TX, USA) was coupled to Protein A/G Plus Agarose for $1 \mathrm{~h}$ and subsequently crosslinked for 30 minutes (following procedures described in section $A$ and $B$ of the protocol, Pierce ${ }^{\circledR}$ Cross-link Immunoprecipitation Kit Manual). ICP4 immunoprecipitation (section E) was conducted incubating $10 \mu \mathrm{g}$ of infected U2-OS cells nuclear extract (see Nuclear proteins extraction from HSV-1 infected cells) overnight at $4{ }^{\circ} \mathrm{C}$ under gentle shaking. ICP4 was eluted with the provided elution buffer (as indicated in section F). The acid $\mathrm{pH}$ of the elution buffer was neutralized adding $5 \mu \mathrm{l}$ of $1 \mathrm{M} \mathrm{Tris-HCl} \mathrm{pH} 9.5$ to the sample, as specified in the purification protocol. The eluted fraction was quantified using the Pierce ${ }^{\mathrm{TM}}$ BCA Protein Assay kit (ThermoFisher Scientific, Monza, Italy) whereas protein integrity was checked by WB.

\section{ICP4 Purification by ultracentrifugation}

Purification of ICP4 by ultracentrifugation was performed as previously described (Imbalzano et al., 1990). Briefly, $5.3 \times 10^{6}$ plated U-2 OS cells were infected with HSV-1 strain $\mathrm{F}$ at an $\mathrm{MOI}$ of 3 in serum-free medium. After $1 \mathrm{~h}$ at $37^{\circ} \mathrm{C}$, cells were washed with $1 \mathrm{X}$ PBS and fresh complete medium was restored. Cells were scraped off $6 \mathrm{hpi}$ and centrifuged at $1250 \mathrm{rpm}$ for $5 \mathrm{~min}$ at $4^{\circ} \mathrm{C}$. Pellets were processed according to the NXTRACT kit (CelLytic ${ }^{\mathrm{TM}}$ NUCLEAR ${ }^{\mathrm{TM}}$ Sigma-Aldrich, Milan, Italy, protocol B), to obtain native and functional nuclear proteins: cell pellets were incubated with 1X hypotonic lysis buffer (10 mM HEPES, pH 7.9, $1.5 \mathrm{mM}$ $\mathrm{MgCl}_{2}, 10 \mathrm{mM} \mathrm{KCl}, 1 \mathrm{mM} \mathrm{DTT}, 1 \%$ protease inhibitor cocktail) for 5 minutes at $4^{\circ} \mathrm{C}$, allowing cells to swell. The suspended cells were centrifuged for 5 minutes $\left(420 \times g\right.$ at $\left.4^{\circ} \mathrm{C}\right)$. Supernatant was discarded and the obtained pellet was resuspended in $1 \mathrm{X}$ hypotonic lysis buffer. The cells were mechanically disrupted and centrifuged for 20 minutes at $10000 \times \mathrm{g}$ at $4^{\circ} \mathrm{C}$. The supernatant (cytoplasmic fraction) was transferred to a new tube while the crude nuclei pellet was resuspended in 80-120 $\mu \mathrm{L}$ of extraction buffer $(20 \mathrm{mM}$ HEPES, $\mathrm{pH}$ 7.9, $1.5 \mathrm{mM} \mathrm{MgCl}_{2}, 420 \mathrm{mM} \mathrm{NaCl}, 0.2 \mathrm{mM}$ EDTA, 25\% (v/v) glycerol, $1 \mathrm{mM}$ DTT, $1 \%$ protease inhibitor cocktail), to allow nuclear proteins isolation. After 30 minutes of incubation at $4^{\circ} \mathrm{C}$, the sample was centrifuged for 5 minutes $\left(17000 \times \mathrm{g}\right.$ at $\left.4^{\circ} \mathrm{C}\right)$ and the supernatant was preserved into a clean chilled tube. The purification of ICP4 was carried out applying the nuclear proteins extract into the Amicon Ultra $-0.5 \mathrm{~mL}$ centrifugal filter unit equipped with a membrane of $100 \mathrm{~K}$ nominal molecular weight limits (NMWL), and subsequently washing with potassium phosphate buffer $(20 \mathrm{mM} \mathrm{PB}$ and $100 \mathrm{mM} \mathrm{KCl})$ According to the manufacturer's protocol, the sample was centrifuged at $14000 \times \mathrm{g}$ for 10 minutes (at $4^{\circ} \mathrm{C}$ ). The purified sample was recovered spinning for 2 minutes at $1000 \times \mathrm{g}$ and finally quantified using the Pierce ${ }^{\mathrm{TM}} \mathrm{BCA}$ Protein Assay kit (ThermoFisher Scientific, Monza, Italy) and stored in aliquots at $-80^{\circ} \mathrm{C}$ until use. Molecular 
weight purified fractions were validated through LC-MS analysis, ICP4 was the highest covered protein, with negligible traces of cellular factors, like Filamin-A retaining minimal scores.

\section{G4-binding proteins cross-linking assay}

Protein nuclear extracts were obtained as described in the pull-down experiment. Biotinylated oligonucleotides $150 \mathrm{pmol}$, folded in $20 \mathrm{mM} \mathrm{PB} \mathrm{pH} \mathrm{7.4,80} \mathrm{mM,} \mathrm{KCl}$, were bound to $50 \mu$ l of streptavidincoated magnetic beads. DNA coupled-beads were activated with formaldehyde (Sigma-Aldrich, Milan, Italy) $5 \%$ for $15 \mathrm{~min}$ at RT and then incubated with nuclear proteins $15 \mu \mathrm{g}$ extract at $4{ }^{\circ} \mathrm{C}$ for $45 \mathrm{~min}$ and proteins excess was washed withTris- $\mathrm{HCl}$ pH7.5 50mM, $150 \mathrm{mM} \mathrm{NaCl}$ solution. Samples were then analyzed by western blot analysis, with an anti-ICP4 antibody (mouse monoclonal H943 Santa Cruz). Briefly, samples were electrophoresed on a $8 \%$ SDS-PAGE and transferred to a nitrocellulose blotting membrane (Amersham TM Protan TM, GE Healtcare Life science, Milan, Italy) by using trans-blot SD semi-dry transfer cell (Bio-Rad Laboratories, Milan, Italy). The membrane was blocked with $2.5 \%$ skim milk in phosphate-buffered saline solution, incubated with the anti-ICP4 antibody (1:100) and then with the ECL Plex Goat- $\alpha-M o u s e$ IgG-Cy5 (GE HealthcareLifesciences, Milan, Italy). Images were captured on Typhoon FLA 9000.

\section{FRET and FRET-melting assays}

For Föster Resonance Energy Transfer (FRET) experiments, oligonucleotides were diluted to $0.25 \mu \mathrm{M}$ in 20 $\mathrm{mM} \mathrm{PB} \mathrm{pH} 7.4$ and 2-80 $\mathrm{mM} \mathrm{KCl}$, heat denatured for $5 \mathrm{~min}$ at $95^{\circ} \mathrm{C}$, and allowed to cool to RT. For the creation of the double strand sequence (ds) the G-rich and the C-rich oligos were added to the same sample $\left(1: 1\right.$ ratio) and heat denaturated for $5 \mathrm{~min}$ at $95^{\circ} \mathrm{C}$. For samples that were tested with the complementary strand, the $\mathrm{C}$-rich oligo was added to the sample $18 \mathrm{~h}$ after denaturation of the G-rich oligo. Samples were incubated alone or with ipICP4/pICP4 or BSA for $1 \mathrm{~h}$ at $4^{\circ} \mathrm{C}$ and subsequently fluorescence intensity was measured in a LightCycler II (Roche, Milan, Italy) by observing 6-carboxyfluorescein (6-FAM) emission. Protein buffers (50mM Tris- $\mathrm{HCl}, 150 \mathrm{mM} \mathrm{NaCl}$ or $20 \mathrm{mM} \mathrm{PB}, 100 \mathrm{mM} \mathrm{KCl}$ ) were added to the oligos, depending on the experiment. The excitation wavelength was set at $480 \mathrm{~nm}$ and the emission was recorded from 500 to $650 \mathrm{~nm}$. In the melting assay, fluorescence was monitored from $30^{\circ} \mathrm{C}$ to $95^{\circ} \mathrm{C}\left(1^{\circ} \mathrm{C} / \mathrm{min}\right)$.

\section{Un2 and G4 visualization in infected cells}

U2-OS cells were plated $\left(2.75 \times 10^{5}\right)$ on glass coverslips and infected, $24 \mathrm{~h}$ post seeding, with HSV-1. Cells were fixed, $8 \mathrm{hpi}$, with $2 \%$ paraformaldehyde $2 \%$ sucrose in PBS $1 \mathrm{X}$ for $10 \mathrm{~min}$ and permeabilized with $0.1 \%$ Tween-20, for $45 \mathrm{~min}$ at RT. Cells were treated with RNAse A $(40 \mu \mathrm{g} / \mathrm{ml})$ for 45 minutes at RT. A quantity of $50 \mathrm{ng}$ of UN2 shifted pla-btn probe (Table S1) was denaturated in hybridization buffer (10\% formamide; $1 \mathrm{X}$ Saline Sodium Citrate (SSC) buffer) for $5 \mathrm{~min}$ at $95^{\circ} \mathrm{C}$ and immediately cooled down on ice. The hybridization reaction on coverslips was carried out with an initial step of $5 \mathrm{~min}$ at $85{ }^{\circ} \mathrm{C}$ and overnight incubation at $37^{\circ} \mathrm{C}$. Coverslips were treated with BlockAid ${ }^{\mathrm{TM}}$ (ThermoFisher Scientific, Monza, Italy) for $1 \mathrm{~h}$ at $\mathrm{RT}$, prior to incubation with the anti $\mathrm{G} 4$ antibody $(1 \mu \mathrm{g} / \mu \mathrm{l})(1 \mathrm{H} 6$, kindly gifted from Prof. Lansdorp PM) and the anti-biotin antibody (1:1000 dilution, Bethyl Laboratories, Inc. Montgomery, TX, USA; ) for $1 \mathrm{~h}$ at RT. Secondary antibodies anti-mouse Alexa 488 and anti-rabbit Alexa 546 (1:300 dilution, ThermoFisher 
Scientific, Monza, Italy) were incubated for $1 \mathrm{~h}$ at RT. All washes were carried out in $1 \mathrm{x}$ PBS $-0.05 \%$ Tween 20.

\section{Proximity ligation assay}

U2-OS cells were plated $\left(2.75 \times 10^{5}\right)$ on glass coverslips and infected with HSV-1. Infected cells were fixed, at $8 \mathrm{hpi}$, with $2 \%$ paraformaldehyde $2 \%$ sucrose in PBS $1 \mathrm{X}$ for $10 \mathrm{~min}$ and permeabilized with $0.4 \%$ Triton X100 , for $5 \mathrm{~min}$ at RT, and treated with RNAse A $(40 \mu \mathrm{g} / \mathrm{ml})$ for 45 minutes at RT, $24 \mathrm{~h}$ after seeding $A$ quantity of $50 \mathrm{ng}$ of UN2 shifted pla-btn probe (Table S1) was denaturated in hybridization buffer (10\% formamide; 1X Saline Sodium Citrate (SSC) buffer) for $5 \mathrm{~min}$ at $95^{\circ} \mathrm{C}$ and immediately cooled down on ice. The hybridization reaction on coverslips was carried out with an initial step of $5 \mathrm{~min}$ at $85^{\circ} \mathrm{C}$ and overnight incubation at $37^{\circ} \mathrm{C}$. Coverslips were treated with BlockAid ${ }^{\mathrm{TM}}$ (ThermoFisher Scientific, Monza, Italy) for $1 \mathrm{~h}$ at $\mathrm{RT}$, followed by $2 \mathrm{~h}$ incubation at RT with the primary antibodies (anti-biotin 1:1000 Bethyl - and anti-ICP4 H943 1:250 Santa Cruz Biotechnology, Inc., Dallas, Texas, USA). The PLA assay was carried out with the Duolink PLA in situ kit, PLA probe anti-rabbit plus, the Duolink in situ PLA probe anti-mouse MINUS and the in situ detection reagent Green (Sigma-Aldrich, Milan, Italy) following the manufacturer's protocol. Nuclei were stained with TOTO3 (1:2000, ThermoFisher Scientific, Monza, Italy) for 20 min at RT. PLA results were visualized using a Leica TCS SP2 confocal microscope (60x objective). All the PLA experiments were performed at least three times independently. For each PLA experiment, the following controls were used: mock cells, infected cells w/o probe, infected cells w/o antibodies.

\section{Cellular Cytotoxicity}

Cytotoxic effects were determined by MTT assay. U2-OS cells were grown and maintained according to manufacturer's instructions (https://www.lgcstandards-atcc.org). Cells were plated into 96-microwell plates to a final volume of $100 \mu \mathrm{L}$ and allowed an overnight period for attachment. The following day, the tested compound (B19) was added to each well and tested in triplicate. Control cells were treated in the exact same conditions. Cell survival was evaluated by MTT assay, $24 \mathrm{~h}$ after treatment: $10 \mu \mathrm{L}$ of freshly dissolved solution of MTT ( $5 \mathrm{mg} / \mathrm{mL}$ in PBS) were added to each well, and after $4 \mathrm{~h}$ of incubation, MTT crystals were solubilized in solubilization solution ( $10 \%$ sodium dodecyl sulphate (SDS) and $0.01 \mathrm{M} \mathrm{HCl}$ ). After overnight incubation at $37^{\circ} \mathrm{C}$, absorbance was read at $540 \mathrm{~nm}$. Data were expressed as mean values of at least three individual experiments conducted in triplicate. The percentage of cell survival was calculated as follows: cell survival $=\left(A_{\text {well }}-A_{\text {blank }}\right) /\left(A_{\text {control }}-A_{\text {blank }}\right) \times 100$, where blank denotes the medium without cells. Each experiment was repeated at least three times

\section{Reporter Assays}

Vectors pGL4.10-ICP4 and pGL4.74 TK (150 ng each) were transfected in $1.2 \times 10^{5}$ U2-OS cells per well onto 12-well plates, using Lipo3000 transfection reagent (Invitrogen, Life Technologies Italia, Monza, Italy). B19 was added to the cell medium $2 \mathrm{~h}$ prior/after transfection at increasing concentrations $(5-20 \mu \mathrm{M})$, to avoid interference, if any, with transfection. Expression of firefly luciferase was determined $24 \mathrm{~h}$ after transfection using the Britelite plus Reporter Gene Assay System (PerkinElmer Inc., Milan, Italy) at a Victor 
X2 multilabel plate reader (PerkinElmer Inc., Milan, Italy), according to the manufacturer's instructions. Cells were lysed in $0.1 \%$ Triton-X100-PBS and protein concentration was determined by BCA assay (Thermo Scientific Pierce, Monza, Italy). Luciferase signals were subsequently normalized to total protein content or cell content, according to the manufacturer's protocol (http://ita.promega.com/ /pdf/resources/pubhub/cellnotes/normalizing-genetic-reporter-assays/). Each assay was performed in duplicate and each set of experiments was repeated at least three times.

\section{ICP4-YFP visualization in cells}

U2-OS cells were plated on glass coverslips $\left(2.75 \times 10^{5}\right)$. Cells were transfected with pICP4-YFP (Everett et al., 2007) (750 ng/well) (kindly gifted by Prof. Roger Everett), $24 \mathrm{~h}$ post seeding. Cells were fixed with $2 \%$ paraformaldehyde $2 \%$ sucrose in PBS $1 \mathrm{X}, 24 \mathrm{~h}$ post transfection and visualized at $40 \mathrm{x}$ and $60 \mathrm{x}$ objective with a Nikon A1Rsi+ Laser Scanning confocal microscope equipped with NIS-Elements Advanced Research software (Nikon Instruments Inc., Melville, USA).

For quantification of ICP4-YFP protein expression, the $488 \mathrm{~nm}$ laser (488 nm excitation and 500-550 nm emission filters) was used with the laser power that was set on the untreated control sample and kept unchanged for the acquisition of all pictures. The fluorescent images were then analysed using the ImageJ Software by selecting one cell at a time and measuring the area, integrated density and mean grey value. Using the calculation for corrected total cell fluorescence (CTCF) = integrated density-(area of selected cell $\times$ mean fluorescence of background readings), the fluorescence intensity of each cell was calculated (McCloy et al., 2014). For each image, a background area was used to normalize against auto-fluorescence. For each experimental condition 6-8 images were acquired with a 40x objective, and all cells per slide were analysed.

\section{B19 treatment of HSV-1 infected cells}

U2-OS cells were plated onto six-wells plates $\left(2.75 \times 10^{5}\right)$. Cells were infected with HSV-1 (MOI of 1$) 24 \mathrm{~h}$ post seeding and treated with increasing concentration of B19 $(3.125-50 \mu \mathrm{M}), 1 \mathrm{hpi}$. Cells were collected 24 hpi and cellular/viral proteins were extracted in RIPA buffer (150 mM NaCl, 5 mM EDTA pH 8, 50 mM Tris$\mathrm{HCl} \mathrm{pH} 8,0.5 \%$ Igepal CA-630, 1x Protease Phosphatase Inhibitor CockTail). Protein concentration was determined and samples $(15 \mu \mathrm{g})$ were denatured at $95^{\circ} \mathrm{C}$ prior to immunoblot analysis.

\section{Immunoblot analysis}

Immunoblot analysis were performed on $8-10 \%$ SDS-PAGE and transferred to a nitrocellulose blotting membrane (Amersham TM Protan TM, GE Healtcare Life science, Milan, Italy) by using trans-blot SD semidry transfer cell (Bio-Rad Laboratories, Milan, Italy). The membranes were blocked with $2.5 \%$ skim milk in PBST (0.05\% Tween 20 in PBS). Membranes were incubated with the respective primary antibody directed against ICP4 (mouse monoclonal H943; Santa Cruz Biotechnology, Dallas, TX, USA), alpha-tubulin (mouse monoclonal; Sigma-Aldrich, Milan, Italy). After three washes in PBST, membranes were incubated with ECL 
bioRxiv preprint doi: https://doi org/10.1101/2020.07.14 202747: this version posted July 14, 2020. The copyright holder for this preprint (which was not certified by peer review) is the author/funder, who has granted bioRxiv a license to display the preprint in perpetuity. It is made available under aCC-BY-ND 4.0 International license.

Plex Goat-a-Mouse IgG-Cy5 (GE Healthcare Life sciences, Milan, Italy). Images were captured on the Typhoon FLA 9000.

For quantification purposes the ImageJ software was used. For each sample ICP4 expression values were normalized on the relative housekeeping signal (alpha-tubulin).

\section{Graphical abstract}

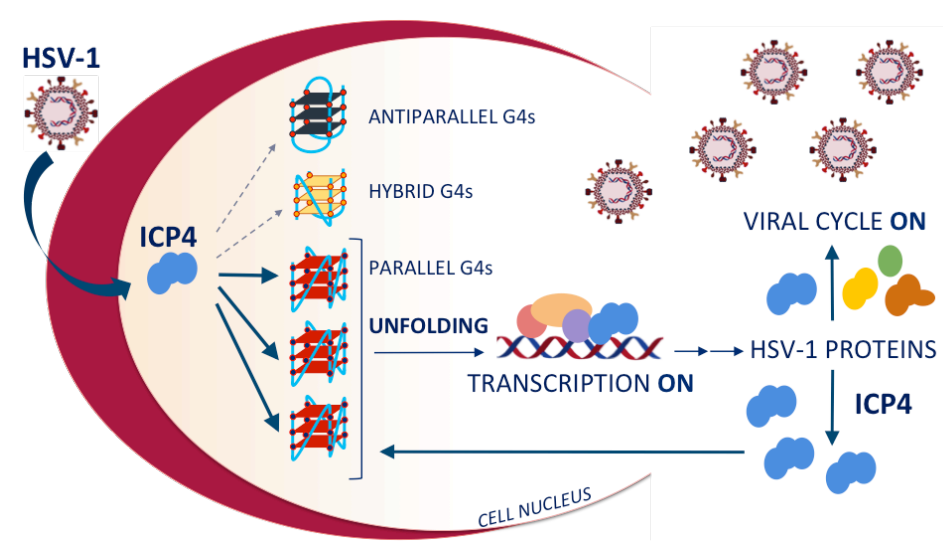

